\title{
Assessment of ICESat-2's Horizontal Accuracy Using Precisely-Surveyed Terrains in McMurdo Dry Valleys, Antactica
}

\author{
Tony Schenk, Beata Csatho and Tom Neumann
}

\begin{abstract}
This paper presents an assessment of the horizontal accuracy and precision of the laser altimetry observations collected by NASA's ICESat-2 mission. We selected the terrainmatching method to determine the position of laser altimeter profiles within a precisely knownn surface, represented by a DEM. We took this classical approach a step further, approximated the DEM by planar surfaces and calculated the optimal position of the laser profile by minimizing the square sum of the elevation differences between reference DEMs and ICESat-2 profiles. We found the highly accurate DEMs of the McMurdo Dry Valleys, Antarctica, ideal for this research because of their stable landscape and rugged topography. We computed the 3D shift parameters of $\mathbf{3 7 9}$ different laser altimeter profiles along two reference ground tracks collected within the first two years of the mission. Analyzing these results revealed a total geolocation error $($ mean $+1 \sigma)$ of $4.93 \mathrm{~m}$ for release 3 and $4.66 \mathrm{~m}$ for release 4 data. These numbers are the averages of the six beams, expressed as mean $+1 \sigma$ and lie well within the mission requirement of $6.5 \mathrm{~m}$.
\end{abstract}

Index Terms-laser altimetry, calibration, ICESat-2.

\section{INTRODUCTION}

$\mathbf{N}$ ASA launched the Ice, Cloud, and land Elevation Satellite-2 (ICESat-2), the successor of ICESat, on September 15, 2018 [1]. ICESat-2 carries the ATLAS (Advanced Topographic Laser Altimeter System) instrument, the first photon-counting laser altimeter in space [2]. ATLAS transmits six laser beams and records each photon's transit time to reconstruct surface height and structure along the satellite's ground track. The ATLAS observations enable the estimation of ice-sheet mass balance and corresponding contributions to sea level rise [3]. Covering our entire planet, ICESat-2 also maps vegetation cover and structure, ocean elevations, and provides shallow coastal bathymetry and geodetic control for earth observations [4].

High accuracy of single-photon geolocation is needed to achieve the mission's primary goal of monitoring land-ice (ice sheet and glaciers) and sea-ice freeboard changes on a centimeter-scale level. Considering the large extent of the Antarctic ice sheets these stringent mission requirements are necessary because small changes in surface height, derived from ATLAS observations, have a considerable impact on mass balance and sea level change estimates. The mission requirement of $0.4 \mathrm{~cm} / \mathrm{yr}$ for ice-sheet elevation change rates

T. Schenk and B. Csatho are with the Department of Geology, University at Buffalo, Buffalo, NY, 14260 USA email: \{afschenk,bcsatho@buffalo.edu

T. Neumann, NASA Goddard Space Flight Center, Greenbelt MD email: thomas.neumann@nasa.gov corresponds to $51 \mathrm{Gt} / \mathrm{yr}$ which is comparable to the uncertainty of current Antarctic ice sheet mass balance estimates [5].

The requirement of $6.5 \mathrm{~m}$ for the horizontal geolocation error on the Earth's surface translates to nearly 3 arcseconds of the direction vector of the laser beam. Changes in sun-orbit geometry induce thermal-mechanical stress that causes timevarying misalignments [6]. This, in turn, requires sophisticated calibration procedures to keep the ever changing errors under control. The calibration identifies errors and corrects them. On the other hand validation is only concerned with quantifying errors. Postlaunch assessments of ICESat-2 observations using corner-cube retro-reflectors and comparisons with precisely mapped terrains indicate a vertical precision of better than 10 $\mathrm{cm}$ and a horizontal accuracy within the mission requirement of 6.5 meters [7], [8], [6].

Here we are concerned with assessing ATLAS's singlephoton horizontal geolocation accuracy and its temporal variation. We employ the method of matching ICESat-2 ground tracks with precisely surveyed terrain. The horizontal accuracy is estimated by finding the geocoded signal photons' best agreement with the reference DEM (Digital Elevation Model) through 3D translations of the ground tracks. The knowledge of the horizontal accuracy is essential because it may introduce a secondary vertical error, as shown in equation $\sigma_{v}=\sigma_{h} \tan \alpha$ with $\sigma_{v}$ the induced vertical error, $\sigma_{h}$ the horizontal error and $\alpha$ the slope angle. Suppose a horizontal error of $\pm 12 \mathrm{~m}$ (equals to the footprint size, [6]) and a typical slope angle at the ice sheet margin of $1^{\circ}$ we obtain a secondary vertical error of $0.21 \mathrm{~m}$-way above the anticipated vertical error of a few centimeters.

We take the traditional terrain-matching method a step further by introducing a mathematical approximation of the natural surface in order to formulate a least-squares approach, allowing us to calculate the location of the best fit between ICESat-2 ground track and known surface. This is a significant improvement as it determines the shift in one step, together with a rigorous error assessment. We consider the translation (shift) vector as a measure for the horizontal accuracy of ICESat-2. Another unique feature of our approach is the temporal aspect: we determine translation vectors for the entire period data are available. At the time of writing this paper we have used data from 9 cycles, spanning the time from October 16, 2018 to October 23, 2020. Our proposed method is general, higly automated and easy to use. Thus it can be used for assessing the performance of other laser altimetry systems. 
Sec. 2 introduces the McMurdo Dry Valleys in East Antrctica that we used as the validation site. Sec. 3 elucidates the mathematical concept of this innovative approach. Later sections provide characteristic results, followed by an error assessment and concluding remarks.

\section{ICESAT-2 VAlidation Site, McMurdo DRY VALLEYS, ANTARCTICA}

The terrain-matching method aims at finding a laser altimeter profile in a known surface. The known reference surface, likely being represented by a DEM, must satisfy certain characteristics to apply this approach. For one, the accuracy of the DEM should be comparable to that of the altimeter system. Equally important is the requirement that no significant changes (e.g., erosion or vegetation growth) occur over time. The DEMs should also have a distinct topographic structure, for example, deep valleys and steep, stable walls oriented in different directions. For detecting time-varying biases of ICESat-2, the DEMs must be located in the polar regions where we have repeat passes of ICESat- 2 .

DEMs that satisfy these stringent requirements are indeed available in the McMurdo Dry Valleys (MDV), East Antarctica (Fig. 1, Table I). Low precipitation, no vegetation, and cold temperatures make the area a polar desert resulting in largely stable landscapes. The first survey of the MDV employed NASA's Airborne Topographic Mapper (ATM) lidar system in the Austral summer of 2000-2001 [9]. The DEMs calculated from the laser observations were successfully used for validating ICESat measurements [10].

However, increasing summer air temperatures in recent decades resulted in destabilization of buried ice and increased surface ablation of the valley glaciers [11], [12]. The most vulnerable regions are the coastal ice-cored Ross Sea Drift deposits and ice-cemented permafrost at the low laying valley floors [13], [11]. Therefore, from December 2014 to January 2015 , about $3600 \mathrm{~km}^{2}$ was resurveyed by NCALM (National Science Foundation's National Center for Airborne Laser Mapping) to determine landscape changes as temperatures increased in the Dry Valleys [11]. As pointed out in [12] the comparison between ATM and NCALM DEMs revealed areas with substantial differences (up to $1 \mathrm{~m}$ ) due to thermokarst subsidence, and glacier thinning, for example. Their study guided the selection of the ground-tracks for this study. We used the NCALM DEMs for our ICESat-2 validation study as they were collected closer in time to the mission.

Along the coast, rapid erosion with rates reaching several meters per year was detected at several sites [12]. Processes causing these significant changes include the deep incision of streams into buried ice and the formation of thermokarst ponds and thaw slumps. Therefore, we excluded the coastal region from this study (e.g., Taylor Valley E and Denton Hill DEMs, [14]).

DEMs covering the selected Reference Ground Tracks (RGTs 275 and 451) are located further inland, in the Mixed Inland Zone (Northern DV North, Middle, and South; Taylor Valley Middle and West DEMs, Table I, Fig. 1). In this region, erosion and deposition along stream and river banks and outlet glacier mass balance changes caused a surface change of $0.05 \mathrm{~m} / \mathrm{yr}$ or less. These changes, usually restricted to short segments of the ICESat-2 ground track, were neglected. However, increasing lake levels, attributed to increasing melt of glaciers and permafrost, were significant during the last few decades [12]. The largest change was detected on Lake Vanda (Wright Valley), where lake level increased with an average rate of $0.3 \mathrm{~m} / \mathrm{yr}$ between $2000 / 01$ and 2014/15. Therefore, we examined all solutions with segments over large lakes and discarded those with large uncertainties.

NCALM used Optech's Titan multispectral airborne laser scanner that rendered two to ten returns per $\mathrm{m}^{2}$ [14]. The geographic coordinates (latitude, longitude) and the elevation of the laser points were calculated in the World Geodetic System, WGS84 ellipsoid, based on ITRF2008. The estimated vertical error of the individual laser points is $\pm 0.07 \mathrm{~m} \mathrm{RMSE}$ [14]. Digital Elevation Models (DEMs) were derived at $1 \mathrm{~m}$ intervals on a regularly spaced grid in the US Geological Survey Transantarctic Mountains Projection (EPSG:3294) system. More detailed information about the laser campaign and data processing can be found in [14].

To provide the best geometry and avoid extremely long segments, we subsetted and combined parts of the original NCALM DEMs into new DEMs that better agree with landscape units, like valley floors with surrounding valley walls (Table II).

\section{A. ICESat-2 Mission and Data Description}

ICESat- 2 orbits Earth at $7 \mathrm{~km} / \mathrm{s}$, at an altitude of about $500 \mathrm{~km}$. The near-polar orbit has an inclination of $92^{\circ}$, producing a coverage between $88^{\circ}$ north and south, with a 91-day exact repeat cycle in the polar regions [2]. The satellite carries ATLAS, a single-photon counting laser altimetry system [2], [1]. ATLAS uses a low energy, green $(532 \mathrm{~nm})$ laser pulse that is split into six individual beams. Each beam illuminates a footprint on the Earth's surface, diameter $\sim 12 \mathrm{~m} \mathrm{[6].}$

The six laser beams are arranged in three pairs: one central pair and two sideward looking pairs. Each pair consists of a strong and a weak beam with the latter approximately four times weaker. By slightly yawing the spacecraft, the array with the six beams is rotated with respect to the flight direction, causing the strong and weak beams of the pairs to be separated by $\sim 90 \mathrm{~m}$ (Fig. 2), thus enabling the determination of the across-track slope. The spot pairs are separated on the ground by $\sim 3.5 \mathrm{~km}$ across-track, and the strong and weak beams of each pair are $\sim 2.5 \mathrm{~km}$ from each other along-track [15]. The ICESat- 2 observatory is re-oriented by rotating it around its nadir axis approximately twice a year to maximize sun illumination on the solar arrays. It was launched in forward orientation, and then rotated to backward orientation on December 28, 2018 (yaw flip). Yaw flips occur approximately every 8 months. Fig. 2 shows the numbering convention of the six beams in forward and backward orientations relative to the direction of travel.

An essential result of laser altimeter observations, such as performed by the ATLAS system of the ICESat-2 satellite, is to determine the location where the laser beam interacts 
TABLE I

CONTAINS DEMS OF MCMURdo DRY VALLEYS (DV) SELECTED FOR THIS STUDY FROM THE NCALM SURVEY IN 2014-15 [14]. ELEVATIONS ARE ON

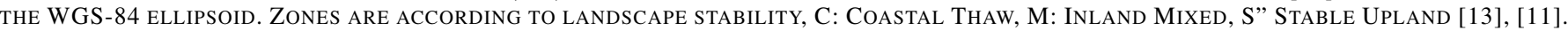

\begin{tabular}{|l|c|c|c|c|}
\hline DEM Name & Abbr. & Geographic features & Elevation $(\mathrm{m})$ & Zone \\
\hline Northern DV North & NDVN & Victoria \& Barwick Valleys & $300-2070$ & $\mathrm{C}, \mathrm{M}$ \\
Northern DV Middle & NDVM & McKelvey Valley, Wright Valley E., Bull Pass & $125-1930$ & C, M, S \\
Northern DV South & NDVS & Wright Valley W, Labyrinth & $-52-1925$ & C, M \\
Taylor Valley West & TVW & Taylor Valley, Taylor Glacier & $270-1950$ & C, M \\
Taylor Valley Middle & TVM & Taylor Valley & $10-1850$ & C, M \\
\hline
\end{tabular}

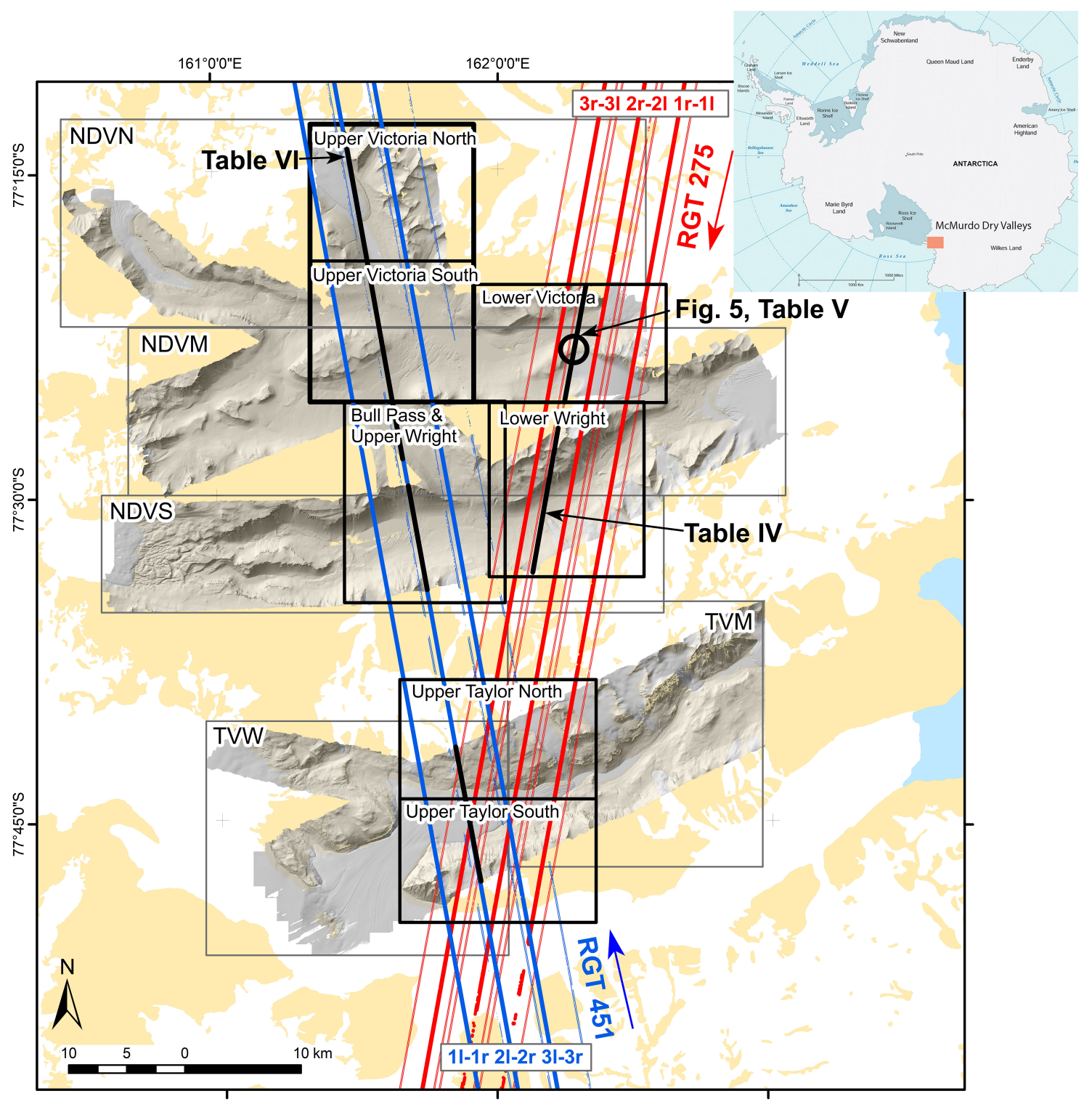

Fig. 1. shows overview of the validation site in the McMurdo Dry Valleys (MDV) with inset in upper right showing MDV in Antarctica. NCALM DEMs covering RGT 275 and 451 are shown as shaded relief maps, and delineated by thin black lines (Table I). DEMs used in this study are generated from subsets of NCALM DEMs and their outlines are shown by thick black lines (Table II). Colored lines are ICESat-2 ground tracks (GT) used in this study: RGT 275 (cycles 1-2: thin and 3 \& 5-9 thick red lines) and 451 (cycles 1: thin and 3-9 thick blue lines). Yellow regions mark rock outcrops, white shows ice sheet and outlet glaciers and blue is Ross Sea (from Antarctic Digital Database, 2000). GT sections highlighted by black are used in examples in Fig. 5, Tables IV-VI.

with the Earth's surface. This process is known as geolocating a laser beam or signal photons and is accomplished with three fundamental measurements: (i) location of the origin of emitting a laser pulse, (ii) the travel direction of the pulse, and (iii) the travel time of the pulse from its origin to the spot it illuminates on the ground and back to ATLAS again. The Precision Orbit Determination (POD) of ATLAS aims at delivering the location of the spacecraft center of mass 
TABLE II

CONTAINS DEMS GENERATED FROM SUBSETS OF NCALM DEMS, TO COVER THE TWO RGTS, 275 AND 451, USED IN THIS STUDY (FIG.1).

\begin{tabular}{|l|l|}
\hline DEM Name & derived from \\
\hline Upper Victoria Valley North & NDVN \\
Upper Victoria Valley South & NDVN \& NDVM \\
Bull Pass \& Upper Wright Valley & MDVM \& NDVS \\
Lower Victoria Valley & NDVN \& NDVM \\
Lower Wright Valley & NDVM \& NDVS \\
Upper Taylor Valley North & TVM \& TVW \\
Upper Taylor Valley South & TVM \& TVW \\
\hline
\end{tabular}

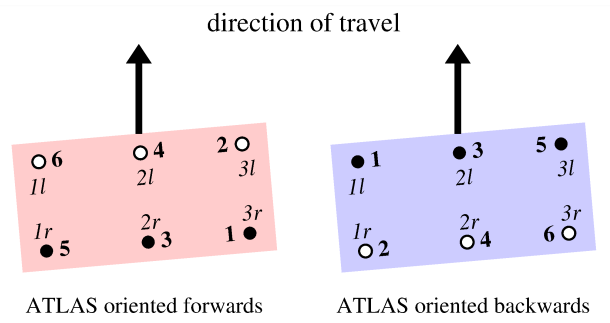

Fig. 2. illustrates beam pattern and numbering convention of the six ATLAS beams, in forward and backward oriented settings. The numbers 1 to 6 , in bold face, are related to the same physical beam, regardless of the array's orientation, while $(11,1 r),(21,2 r)$ and $(31,3 r)$ are referring to beam pairs 1 (left), 2 (center) and 3 (right) relative to the direction of travel of the satellite Strong beams (1, 3 and 5) are marked with filled circles. Derived from [1], Fig. 8

and the offset vectors to ATLAS [16]. The Precision Pointing Determination (PPD) is tasked with the determination of the direction of the laser beam [17]. The horizontal accuracy of the location of the laser spot (or footprint) depends mostly on the uncertainty of the direction vector.

The ATLAS/ICESat-2 L2A Global geolocated Photon Data (ATL03) product of the ICESat-2 mission contains the geolocation of each photon event downlinked from ATLAS [2], [1]. The geolocations are given as latitude, longitude, and elevation with respect to the WGS84 ellipsoid based on ITRF2014. In addition, ancillary data are provided, such as landcover type (land ice, sea ice, land, ocean) and the classification of photon events into signal photons with different confidence levels and noise photons. According to the photon classification in the ATL03 product, Class 4 is assigned to high-confidence photons that were most likely reflected from the Earth's surface. Classes 3 and 2 indicate signal photons with lower confidence levels. Class 1 is assigned to likely background photons to provide a buffer zone around the surface [1].

Since the DEMs are given in the USGS Transantarctic Mountains Projection (EPSG:3294) system we adopted this system for all the computations. The difference between the ITRF systems used for the DEMs and ATL03, i.e., ITRF2008 versus ITRF2014 results in very small differences (mm level, personal communication, Andrew Fountain, 2020). Therefore, we didn't apply a transformation to account for the different ITRFs. Also because we are concerned in this study with the horizontal error of ICESat-2 small height differences do not impact our results.

From ATL03, higher-level data products, such as the Land
Ice Along-Track Height Product, ATL06 [18], yielding land ice elevation at every 20 meters along-track are derived. Although its smaller data volume makes it easier to work with ATL06 data, we elected to use the ATL03 product. ATL03 includes pulses that are $0.7 \mathrm{~m}$ apart with a few signal photons in each pulse. Thus it gives a more detailed representation of the terrain and increases the data redundancy in our algorithms, leading to more robust solutions. Sec. IV-B provides a more detailed rationale for using the ATL03 data product.

ATL03 and ATL06 products, which are publicly available, were obtained from the National Snow and Ice Data Center (NSIDC) [19], [20]. Most results in this study are derived from ATL03 data, release 4, except those from release 3 data product used to demonstrate the improvement of horizontal accuracy of ICESat-2. We used observations collected from RGT 275 (descending) and 451 (ascending), cycles 1-9, covering the time span $10 / 16 / 2018$ to $10 / 23 / 2020$.

TABLE III

LISTS 2 RGTS AND THE DATES WHEN CROSSING THE MCMURDO DRY VALLEYS. RGT 275 IS DESCENDING AND 451 IS ASCENDING. SEE FIG. 1 FOR LOCATION OF GTS.

\begin{tabular}{|c|r|r|}
\hline cycle & RGT 275 & RGT 451 \\
\hline 1 & $10 / 16 / 2018$ & $10 / 28 / 2018$ \\
2 & $1 / 15 / 2019$ & $1 / 22 / 2019$ \\
3 & $4 / 16 / 2019$ & $4 / 27 / 2019$ \\
4 & & $7 / 27 / 2019$ \\
5 & $10 / 14 / 2019$ & $10 / 26 / 2019$ \\
6 & $1 / 13 / 2020$ & $1 / 25 / 2020$ \\
7 & $4 / 13 / 2020$ & $4 / 25 / 2020$ \\
8 & $7 / 13 / 2020$ & \\
9 & $10 / 12 / 2020$ & $10 / 23 / 2020$ \\
\hline
\end{tabular}

\section{Methodology}

In spaceborne laser altimetry systems the laser beams are fixed with respect to the platform-in contrast to commercial airborne scanning systems. The ground tracks of ICESat-2's laser beams consist of a sequence of $3 \mathrm{D}$ points, corresponding to geolocated photons, calculated from observed angles and positions of the platform, together with the range. We refer to these computed locations as laser points and call a segment of consecutive laser points a laser profile, represented as distance/height pairs. It is worth to remember that a computed laser point is not identical with the spot on the ground (physical or true location) from where the photon is reflected back into space.

The green spot in the schematic diagram of Fig. 3 depicts the true location on the Earth's surface from where the laser beam was reflected. We will never know its exact location but rather have to rely on a computed position achieved with the pointing knowledge, after post-processing. This reconstructed location is marked by the blue spot. The red spot shows the location of best agreement of an ICESat-2 GT within a precisely known DEM, found by the approach described in Sec. III-A. The vector from the blue to the red spot is called translation vector in this study. Its magnitude is used to estimate the horizontal accuracy of the ATL03 data product.

The traditional approach of finding the location with the best agreement between a laser profile and a DEM is to generate 


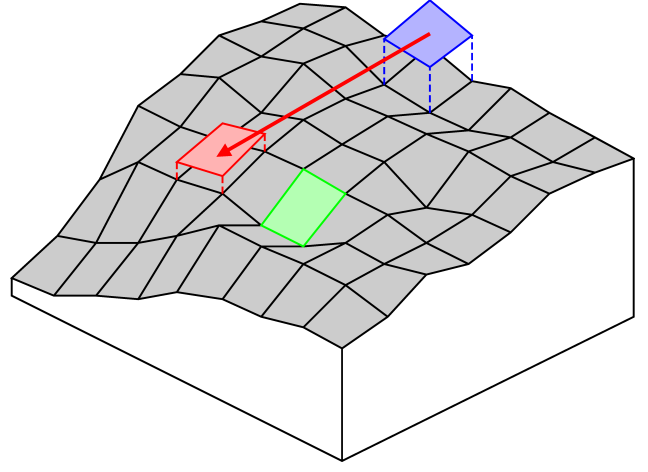

Fig. 3. shows 3 colored surface patches: green is the true location of the illuminated spot on the ground. Blue is the reconstructed position provided in the ICESat-2 data (e.g., ATL-03), and red marks the refinement by the method in this study. The translation vector goes from the reconstructed to the refined positions (from blue to red patches).

a DEM profile at the location of the laser profile (e.g., [21], [22], [8]). Then the height differences between the two profiles serve as a measure for the closeness. These steps are repeated at shifted locations until the point of best agreement is found. The problem with this traditional approach is that there is no way to predict where the location with the best agreement is and one is forced to compute the height differences at every point within the search space. Moreover it is not obvious how one can derive rigorous error quantities of the location of best agreement.

\section{A. Principle}

We have improved the traditional approach by casting it as an ordinary least squares adjustment. For obtaining an analytical function of the difference between the laser and DEM profiles we approximate the DEMs by planar surface patches in the vicinity of the ICESat-2 ground tracks. The idea of approximating natural surfaces with analytical functions to find the best match of a laser profile in a DEM has been originally proposed by [23], [24], [25].

We summarize the ordinary least squares method with a Gauss-Markov model as follows [26]

$$
\boldsymbol{y}=\boldsymbol{A} \boldsymbol{x}+\boldsymbol{e} \quad \text { with } \quad \mathrm{E}(\boldsymbol{e}=\mathbf{0}) \text { and } \operatorname{Cov}\left(\sigma^{2} \boldsymbol{I}\right)
$$

with $\boldsymbol{y}$ the observation vector, $\boldsymbol{A}$ the design matrix, $\boldsymbol{x}$ the vector with the unknowns to be estimated and $\boldsymbol{e}$ the random error vector. The Gauss-Markow model specifies that the errors have a zero mean and are not correlated. From Eq. 1 we build the normal equation matrix, $\boldsymbol{N}$, from which we can estimate the unknown vector $\boldsymbol{x}$ if $\boldsymbol{N}^{-1}$ exists.

$$
\begin{aligned}
\boldsymbol{N} & =\boldsymbol{A}^{T} \boldsymbol{P}^{-1} \boldsymbol{A} \\
\hat{\boldsymbol{x}} & =\boldsymbol{N}^{-1} \boldsymbol{y}
\end{aligned}
$$

$\boldsymbol{P}$ in Eq. 2 is the weight matrix. If all weights are equal it can be replaced by the identity matrix, $\boldsymbol{I}$. Apart from the unknown vector we also obtain a consistent error estimate for the errors of the unknowns as long as the conditions imposed by the Gauss-Markov model hold.

Now we specify the mathematical model for our problem to determine the location with the best agreement between a laser profile and a DEM. Bearing in mind that the DEM is approximated by planar surface patches we can compute the shortest distance of an ICESat-2 laser point to a surface patch as follows:

$$
d=x \cos \alpha+y \cos \beta+z \cos \gamma-\rho
$$

with $\cos \alpha, \cos \beta, \cos \gamma, \rho$ the plane parameters, $x, y, z$ the coordinates of the laser point and $d$ the perpendicular distance to the plane.

To model the error of the laser system, we introduce in Eq. 4 an unknown translation vector $\boldsymbol{t}=(\Delta x, \Delta y, \Delta z)$ and obtain

$$
d=(x+\Delta x) \cos \alpha+(y+\Delta y) \cos \beta+(z+\Delta z) \cos \gamma-\rho
$$

This equation is linear with respect to the unknown translation vector. Rearranging leads to the following linear observation equation of a least-squares adjustment:

$$
\begin{aligned}
\operatorname{res}_{i j}= & \cos \left(\alpha_{j}\right) \cdot\left(\Delta x+x_{i}\right)+\cos \left(\beta_{j}\right) \cdot\left(\Delta y+y_{i}\right)+ \\
& \cos \left(\gamma_{j}\right) \cdot\left(\Delta z+z_{i}\right)-\rho_{j}
\end{aligned}
$$

where the index $i$ runs from 1 to the total number of points in plane $\mathrm{j}$ and index $\mathrm{j}$ runs from 1 to the total number of planes involved. Since the adjustment problem is linear, no approximations of the three unknown components of the translation vector are necessary. Moreover, the adjustment not only delivers estimates for the unknowns but also for their errors.

\section{B. Workflow}

The workflow entails four major steps. In every step the computations are repeated independently for all six beams of ICESat-2. The first processing step selects one ground track and subsets it to the DEM. At the same time, it examines the ATL03 photon distribution for suitability for further processing. Large gaps in the data or obvious blunders may be reasons to reject the ground track. We pass on to the next processing step and use only signal photons of Class 2 or higher. Note that only one DEM/GT combination is used in the same processing step, referred to as a computational unit in this paper. If the same ground track traverses another DEM, a new translation vector will be computed.

The primary purpose of the second processing step is to analyze the signal photon distribution in each pulse. Under very favorable conditions we may expect up to a dozen photons for strong beams and approximately one fourth of it for weak beams [2]. In case of multiple photons we determine the average height and compute the error (standard deviation) as a measure for the precision of the averaged photon height. Multiple photon events also provide the opportunity to determine and eliminate blunders, although the low redundancy renders this process not very reliable. 
The third step of our procedure to determine translation parameters involves the computation of planes of the DEM, along the trajectory of the ICESat-2 beam. This requires the approximation of the DEM by a succession of planar surface patches. The size of a surface patch depends on the topography of the DEM, its sampling size and the magnitude of the anticipated translation vector. Considering these factors we have chosen a size of $50 \mathrm{~m} \times 50 \mathrm{~m}$ for a surface patch. With a DEM grid spacing of $1 \mathrm{~m}$ we obtain an impressive redundancy of 2497 , leading to a robust error analysis of the fitted planes. Surface patches with fitting errors greater than $1 \mathrm{~m}$ were rejected. In this step we also solve the correspondence problem between ICESat-2 laser points and surface patch in that every surface patch has a list of associated points.

The fourth step consists of executing the least-squares algorithm described in Sec. III-A. The result gives an estimate for the mean translation vector for the given computational unit and the error of this estimate. Since the adjustment is linear, no approximations for the unknown parameters are required and no iterations are necessary.

\section{Additional Information}

In order to facilitate the comparison of the translation vector with other results and to provide a direct relationship of the translation vector to the direction vector of ICESat-2's precision pointing system we perform a fifth step to transform the horizontal coordinates to a local ground track system (Fig. 4).

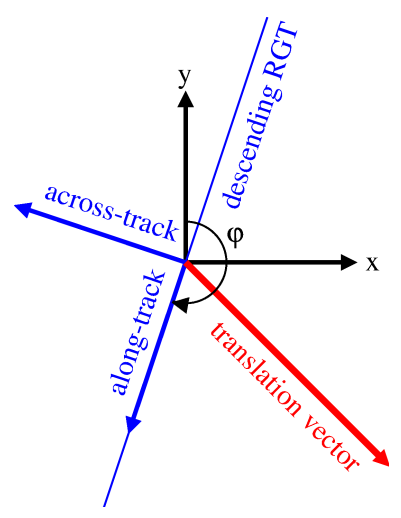

Fig. 4. calculation of translation vector is performed in US Geological Survey Transantarctic Mountains Projection (EPSG:3294) $x, y, z$ system and then transformed into the local across-track/along-track system.

As the figure illustrates, the positive along-track axis points to the travel direction of the satellite and the positive acrosstrack axis is perpendicular, pointing to the right of the travel direction. The across- and along-track axes form a righthanded coordinate system.

Table IV contains useful statistical information related to beams 3 (strong) and 4 (weak) of RGT 275, cycle 1, when it crosses the Lower Wright Valley DEM (Fig. 1). Remember from Sec. III-B the process of calculating the closest distance between an ICESat-2 profile and its corresponding DEM profile begins with selecting signal photons from the ATL03 data set. There is usually more than one signal photon per pulse (Table IV, column 4). In that case we take the mean as a representative value for the pulse and also calculate the standard deviation, $\sigma$. If only one signal photon per pulse is available then we compare it with signal photons of neighboring pulses and accepted it if the height difference is below a user selectable threshold.

TABLE IV

CONTAINS USEFUL INFORMATION ABOUT CENTRAL BEAM PAIR (BEAM 3 AND 4) OF RGT 275, CYCLE 1, LOWER WRIGHT VALLEY DEM. GTS ARE HIGHLIGHTED IN FIG. 5 (BLACK LINE). COL. 4 SHOWS THE TOTAL NUMBER OF PULSES HAVING MORE THAN ONE SIGNAL PHOTON. MEAN IS USED AS A REPRESENTATIVE VALUE OF MULTIPLE PHOTONS. THE LAST TWO COLUMNS LIST THE NUMBER OF PLANES AND POINTS ASSOCIATED WITH PLANES.

\begin{tabular}{|c|c|c|c|c|c|c|}
\hline beam & $\begin{array}{c}\text { total } \\
\text { signal } \\
\text { photons }\end{array}$ & $\begin{array}{c}\text { total } \\
\text { number } \\
\text { pulses }\end{array}$ & $\begin{array}{c}\text { pulses with } \\
\text { signal } \\
\text { photons }>1\end{array}$ & $\begin{array}{c}\sigma \\
{[\mathrm{m}]}\end{array}$ & $\begin{array}{c}\text { total } \\
\text { number } \\
\text { planes }\end{array}$ & $\begin{array}{c}\text { total } \\
\text { number } \\
\text { points }\end{array}$ \\
\hline 3 & 64537 & 15623 & 12682 & 0.73 & 224 & 15623 \\
4 & 19367 & 10405 & 5128 & 0.67 & 227 & 10405 \\
\hline
\end{tabular}

The DEM must be approximated by planar surface patches to enable a mathematical approach for determining the best fit of the ICESat-2 profile with the DEM (Sec. III-A). Column 6 in Table IV contains the total number of accepted planar surfaces and the last column lists the total number of ATL03 laser points participating in the adjustment.

\section{RESUlts}

\section{A. Comparison of ICESat-2 Elevations and DEMs Before and After Adjustment}

Fig. 5 illustrates the ICESat-2 measurements along a 900meter segment of RGT 275 as it crosses the Robinson Ridge between Victoria Valley and Clark Glacier on October 16, 2018 (Fig. 5(b)). Selected is the strong beam of the central pair (beam 3 or GT2r, see Fig. 2). Fig. 5(a) shows the distribution of the geolocated photons (ATL03) and the land ice elevation product (ATL06) for the strong beam over the crest of the ridge. The high confidence signal photons (Class 4) are shown by red dots, while low confidence signal photons in Class 3 and 2 are blue and black, respectively. Large filled green circles refer to ATL06 data. The large vertical spread of the signal photons is typical over rugged surfaces where the calculation of the surface from the ATL03 point cloud becomes difficult. The black line represents the surface elevation from the reference DEM at the original positions of the ATL03 photons along the GT.

As Fig. 5(a) shows, most of the ATL03 photons are below the DEM in this profile, underestimating the surface elevation compared to the reference DEM by up to more than one meter over the steepest slope (Fig. 5(d)). Using our approach, we obtained a translation vector of $(3.15 \pm 0.07,-1.73 \pm$ $0.05,0.24 \pm 0.01)$ meters for the computational unit encompassing this ICESat-2 profile. After shifting the ATL03 photons with this translation vector, they show significantly improved agreement with the reference DEM, indicating that most of the horizontal error is removed (Fig. 5(e)). The linear 


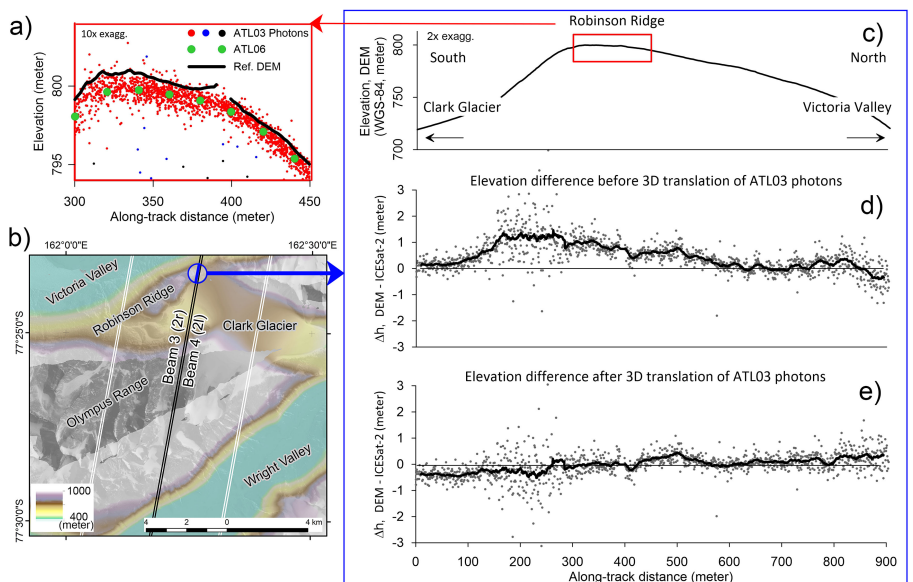

Fig. 5. shows results from RGT 275, cycle 1, October 16, 2018 over the Robinson Ridge within the Lower Victoria Valley DEM (circled in Fig. 1). a) Beam 3 (GT2l) classified signal photons across the Robinson Ridge, (within red box in c); red dots: Class 4; blue dots: Class 3; black dots: Class 2 photons. Large green filled circles are ATL06 elevations. Solid black line represents DEM elevation. b) Location of ICESat-2 GTs over DEM, beams 3 and 4 are shown by black lines and other GTs are white. Elevations from reference DEM and ICESat-2 beam 3 (GT2l) within blue circle are used in c)-e). c) Topography from DEM along beam 3 GT. d) Elevation difference between the surface height estimated as the average of the signal photon height for each pulse at the original geolocation of the ICESat- 2 pulses and the reference DEM. e) Same difference as in d) after the ICESat-2 photons are shifted according to the translation vector (see Sec. 3.2 for details).

trend in the remaining difference could be attributed to shortterm variations in ICESat-2 pointing errors. By assuming a constant translation vector within each DEM, our method only recovers the mean of this translation vector, but not its shortterm variations.

\section{B. Comparison of Translation Vectors Estimated from ATLO3 and ATLO6}

We have also performed experiments with the ATL06 data product [18]. ATL06 data is derived from ATL03 and is represented in an along-track system at $20 \mathrm{~m}$ segments. ATL06 also takes the additional step of correcting the asymmetry of the transmit pulse shape, together with correcting to remove the first-photon bias [18]. Despite these advantages, we have chosen ATL03 because its point density is much higher which leads to a more faithful representation of the surface. The $20 \mathrm{~m}$ interval of ATL06 data may be an undersampling of more rugged surfaces. The confidence in the calculated translation vector increases with the number of surface patches used in the adjustment inluding the number of ICESat-2 laser points associated with a surface patch. We have to find a compromise between the number of DEM grid points used to approximate the surface patch (as many as possible), the fitting error of the approximation (as low as possbile), and the density of the ICESat-2 ground track (ATL03 or ATL06).

Suppose we select a surface patch size of $30 \mathrm{~m} \times 30 \mathrm{~m}$. This would render 900 DEM grid points to support the approximation by a plane. ATL06 would only have a maximum of two points associated with that surface patch. On the other hand ATL03 will have some 42 points covering the same patch, thus
TABLE V

SHOWS DIFFERENCES IN TRANSLATION VECTORS COMPUTED WITH ATL03 AND ATL06 DATA, RGT 275, CYCLE 1, OCTOBER 16, 2018, ALL 6 BEAMS, LOWER Victoria VALLEY DEM (BLACK LINE IN Fig. 1)).

"ACROSS" AND "ALONG" REFER TO THE ACROSS-/ALONG-TRACK COORDINATE SYSTEM (FIG. 4).

\begin{tabular}{|c|c|c|c|c|c|c|}
\hline \multirow{3}{*}{ beam } & \multicolumn{4}{|c|}{ translation vector } & \multicolumn{2}{c|}{ difference } \\
\cline { 2 - 6 } & \multicolumn{2}{|c|}{ ATL03 } & \multicolumn{2}{c|}{ ATL06 } & \multicolumn{2}{c|}{ ATL03 - ATL06 } \\
\cline { 2 - 6 } & $\begin{array}{c}\text { across } \\
{[\mathrm{m}]}\end{array}$ & $\begin{array}{c}\text { along } \\
{[\mathrm{m}]}\end{array}$ & $\begin{array}{c}\text { across } \\
{[\mathrm{m}]}\end{array}$ & $\begin{array}{c}\text { along } \\
{[\mathrm{m}]}\end{array}$ & $\begin{array}{c}\text { across } \\
{[\mathrm{m}]}\end{array}$ & $\begin{array}{c}\text { along } \\
{[\mathrm{m}]}\end{array}$ \\
\hline 1 & 1.186 & -7.108 & 1.047 & -7.287 & 0.139 & 0.179 \\
2 & -1.451 & -1.993 & -1.586 & -2.108 & 0.135 & 0.115 \\
3 & -3.412 & 1.134 & -3.514 & 1.043 & 0.102 & 0.091 \\
4 & -1.236 & -2.211 & -1.360 & -2.337 & 0.124 & 0.126 \\
5 & -6.064 & 0.916 & -6.325 & 0.862 & 0.261 & 0.054 \\
6 & 0.431 & -3.096 & 0.266 & -3.118 & 0.165 & 0.022 \\
\hline mean & -1.758 & -1.758 & -1.912 & -2.158 & 0.154 & 0.098 \\
stdev & 2.650 & 2.650 & 2.681 & 3.054 & 0.056 & 0.055 \\
\hline
\end{tabular}

increasing the redundancy and making the adjustment much more robust.

The last two columns of Table $\mathrm{V}$ show the differences between the translation vector computed with ATL03 and ATL06 data, respectively. These differences are rather small but not entirely random as the non-zero mean in the second last line and the positive sign of all six differences clearly show. A plausible reason for the bias is the fact that ATL06 is corrected for several geophysical errors while ATL03 data is not. This causes a vertical bias in ATL03 which, in turn, impacts the translation vector [7].

\section{Representative result, one ground-track}

Table VI lists results of the central beam pair of RGT 451 , cycle 3 . This example is representative for the accepted translation vectors. DEM length refers to the length of the overlapping ICESat-2/DEM profile (computational unit) and the remaining two columns show the estimated errors of the translation vector. These errors are computed during the leastsquare solution of the translation vector and are based on the assumption that the observations (ATL03 signal photons) are uncorrelated and their errors are normally distributed.

We determine the translation vector along an overlapping ICESat-2/DEM profile, the length of which depends on several factors such as a vivid topography with surface slopes oriented in distinctly different directions. The lengths of the profiles used in this study are ranging between 4 and $16 \mathrm{~km}$. Thus it takes ICESat-2 one to two seconds to traverse one DEM and less than 10 seconds to cross the entire region of the McMurdo Dry Valleys. We assume that within such short time intervals only small, high-frequency (jitter) variations have an impact on the geolocation of ICESat-2. The schematic diagram of Fig. 6 depicts a five second long interval along an ICESat-2 ground track, crossing three DEMs. The red line symbolizes highfrequency noise that impacts the translation vectors (blue solid circles), determined in the least-squares adjustment (Table VI). We can conceive these values as the means of the translation vectors that are influenced by the high-frequency variations within short time spans as ICESat-2 crosses individual DEMs. 
TABLE VI

CONTAINS TRANSLATION VECTORS AND THEIR ERRORS CALCULATED FOR THE CENTRAL BEAM PAIR 3 AND 4, RGT 451, CYCLE 3, APRIL 27, 2019. DEMS INVOLVED: UVN = UPPER VICTORIA NORTH, UVS = UPPER VICTORIA SOUTH, BP = BULL PASS \& UPPER WRIGHT, UTN $=$ UPPER TAYLOR NORTH, UTS = UPPER TAYLOR SOUTH (FIG. 1).

\begin{tabular}{|c|c|c|c|c|c|c|c|c|}
\hline \multirow[b]{2}{*}{$\begin{array}{r}\text { be } \\
\text { am }\end{array}$} & \multicolumn{3}{|c|}{ translation vector } & \multicolumn{2}{|c|}{ DEM } & \multicolumn{3}{|c|}{ accuracy } \\
\hline & $\begin{array}{c}\text { across } \\
{[\mathrm{m}]}\end{array}$ & $\begin{array}{c}\text { along } \\
{[\mathrm{m}]}\end{array}$ & $\begin{array}{r}\mathrm{mag} \\
{[\mathrm{m}]}\end{array}$ & name & $\begin{array}{c}\text { length } \\
{[\mathrm{km}]}\end{array}$ & $\begin{array}{c}\sigma_{\mathrm{ac}} \\
{[\mathrm{m}]}\end{array}$ & $\begin{array}{r}\sigma_{\mathrm{al}} \\
{[\mathrm{m}]}\end{array}$ & $\begin{array}{c}\sigma_{\mathrm{mag} g} \\
{[\mathrm{~m}]}\end{array}$ \\
\hline \multirow{5}{*}{3} & -1.71 & 1.43 & 2.23 & UVN & 11.1 & 0.07 & 0.06 & 0.09 \\
\hline & -1.86 & 0.72 & 1.9 & UVS & 12.4 & 0.02 & 0.10 & 0.10 \\
\hline & -2.02 & 1.27 & 2.39 & BP & 16.3 & 0.01 & 0.14 & 0.14 \\
\hline & -3.61 & 0.99 & 3.75 & UTN & 4.1 & 0.02 & 0.13 & 0.13 \\
\hline & -1.42 & 0.82 & 1.64 & UTS & 7.2 & 0.02 & 0.09 & 0.09 \\
\hline \multirow{5}{*}{4} & -2.33 & -1.13 & 2.59 & UVN & 11.1 & 0.11 & 0.09 & 0.14 \\
\hline & -1.94 & -2.85 & 3.45 & UVS & 12.4 & 0.04 & 0.12 & 0.12 \\
\hline & -1.97 & -2.60 & 3.26 & BP & 16.3 & 0.01 & 0.27 & 0.27 \\
\hline & -2.13 & -2.93 & 3.62 & UTN & 4.1 & 0.04 & 0.19 & 0.19 \\
\hline & -0.88 & -3.16 & 3.28 & UTS & 7.2 & 0.04 & 0.09 & 0.10 \\
\hline
\end{tabular}

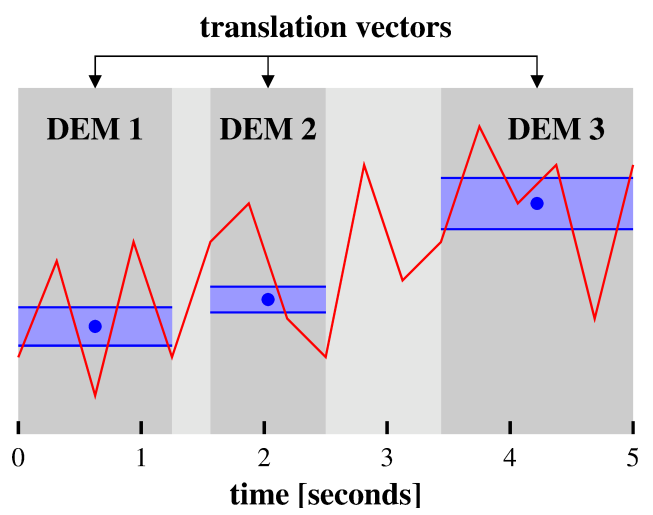

Fig. 6. depicts a 5 second long $(35 \mathrm{~km})$ GT crossing 3 DEMs. The red line symbolizes the horizontal error of ATL03, including a high-frequency noise (jitter) component. Blue solid circles are indicating the computed translation vectors. Dark blue bands centered at translation vectors symbolize uncertainties of the translation vectors.

\section{Entire RGT 275 and 451 Data Set}

We processed a total of 405 translation vectors and accepted 379 that satisfied the following criteria: kappa $<20, \sigma_{\text {across }}<$ $1 \mathrm{~m}, \sigma_{\text {along }}<1 \mathrm{~m}$. Kappa (ratio of maximum eigenvalue over minimum value) is a good indicator for the stability of the normal equation system.

Fig. 7 depicts the temporal relationship of the translation vectors of all beams for RGTs 275 and 451, during 739 days of the mission (nine cycles). Several dots plotted at the same time indicate that a ground track traversed several DEMs during the same repeat cycle. Differences between the translation vectors are attributed to short-term variations discussed in Sec. IV-C. For example beam 3 of RGT 451, cycle 3, crossed 5 DEMs, resulting in 5 translation vectors (see also Table VI).

\section{ASSESSMENT OF ICESAT-2 GEOLOCATION ERRORS}

As pointed out in Sec. I we are concerned in this study with assessing the horizontal accuracy and precision of ICESat-2 ground tracks. This is important because a horizontal error will induce a secondary vertical error, proportional to the distance of the horizontal error multiplied by the slope of the terrain.
We use the translation vectors to estimate the horizontal error of the geolocated signal photons of the ATL03 data product. To achieve the required accuracy of the ICESat2 geolocated photons, their reconstructed location should be within $6.5 \mathrm{~m}$ of their true, but unknown locations (Fig. 3). Our goal is to check if the latest release of ATL03 products is satisfying this condition.

We now turn our attention to the long-term variation of the ICESat-2 horizontal error, estimated from 379 translation vectors, considering the entire observation interval of 739 days. The results are summarized in Fig. 7 and Table VII. Statistics (mean and standard deviation for each beam and all beams), characterizing the ICESat-2 geolocated photons' horizontal errors, for release 3 and 4, are shown in columns $2-7$. The total error refers to mean $+1 \sigma$. Also added to the table are results reported by [6], obtained with release 3 data.

Comparing release 3 and 4 results from this study shows only a modest improvement of ICESat- 2 horizontal accuracy (columns 4 and 7, $4.93 \mathrm{~m}$ vs $4.66 \mathrm{~m}$ ). However, there is a significant drop in the standard deviation of the horizontal error for all beams $(\sigma)$ from $1.09 \mathrm{~m}$ to $0.62 \mathrm{~m}$, suggesting that the horizontal errors of the six ICESat- 2 beams determined from release 4 data are more narrowly distributed than from release 3 data. Both releases show beam 1 having the largest error and beam 5 the smallest error. The horizontal error of beams 1,2 and 4 decreased significantly from release 3 to $4(10-20 \%)$, while errors of beams 2, 5 and 6 remained unchanged or slightly increased, The visual inspection of Fig. 7 reveals that no trend can be discerned over the entire observation period of 739 days.

When comparing the release 3 data reported in Table VII with those reported by [6], also obtained with release 3 , one should bear in mind some important differences in how the two data sets are computed, e.g. the geographic region and its extent (entire ArcticDEM vs. MDV Antarctica), the different methods used to determine ICESat-2 track offsets, and the horizontal accuracy of the DEMs. Looking at the estimated ICESat-2 horizontal errors, one can conclude that they are, perhaps suprisingly, rather small and well within the $6.5 \mathrm{~m}$ geolocation requirement. We also notice that values from [6] are consistently lower than those from this study (both derived from release 3). This could be attributed to the fact that including ICESat-2 observations over the entire Arctic generates a multitude of data and thus lowers the error.

\section{DISCUSSION AND CONCLUDING REMARKS}

The prime objective of this paper is to assess the horizontal accuracy of ICESat-2. We have improved the traditional method of matching a laser profile with a precisely known surface, likely being represented as a DEM, by casting it as a least-squares adjustment. This novel approach does not only offer the calculation of the 3D translation vector but provides rigorous information about error quantities related to the unknowns.

We have selected the McMurdo Dry Valleys (MDV), East Antarctica, as our known surface because the DEMs are very accurate ( $1 \mathrm{~m}$ resolution, $0.07 \mathrm{~m}$ RMS $)$, have very stable 

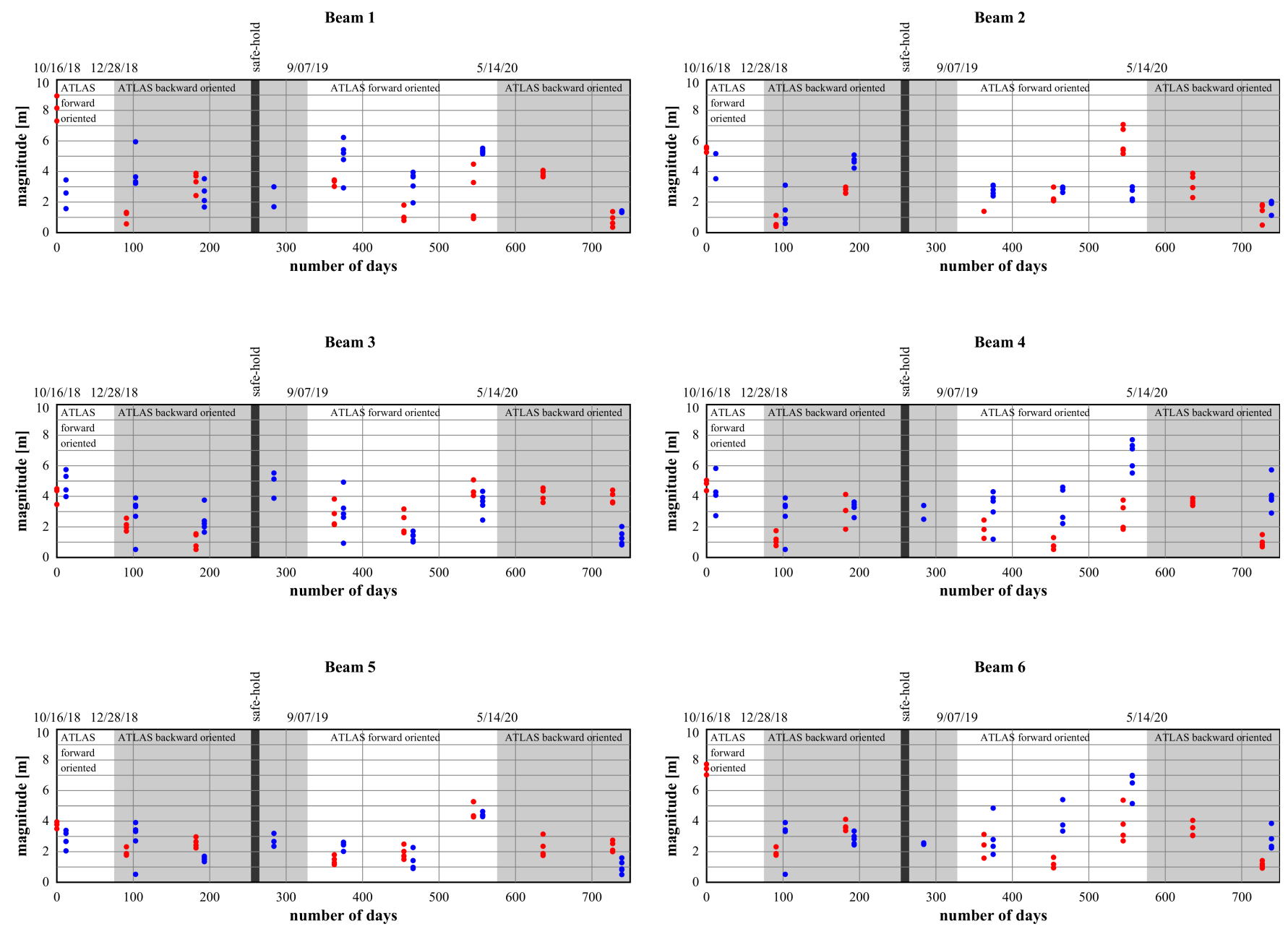

Fig. 7. depicts magnitude (length) of translation vector as a function of time, estimating ICESat-2 horizontal geolocation errors for all six beams. Red dots are marking results from RGT 275 (descending) and blue dots refer to ascending RGT 475. Time is shown as MMDDYY (top of panel) and in number of days (bottom). The observation interval spans the period October 16, 2018, to October 23, 2020, cycle 1 through 9 , for a total of 739 days. Accuracy of the magnitude of translation vector is on the order of 0.05-0.25 m (Table VI) and too small to show.

TABLE VII

SHOWS GEOLOCATION ERRORS OF ICESAT-2. RESULTS ARE ARRANGED IN 3 GROUPS: RELEASE 3 AND 4 (THIS STUDY) AND FROM ARCTICDEM [6] NUMBERS REFER TO THE LENGTH OF THE TRANSLATION VECTOR (MAGNITUDE).

\begin{tabular}{|c||c|c|c||c|c|c||c|c|c|}
\hline \multirow{2}{*}{\begin{tabular}{c}
\multirow{2}{*}{$\begin{array}{c}\text { beam } \\
\text { number }\end{array}$} \\
\cline { 2 - 10 }
\end{tabular}} & $\begin{array}{c}\text { mean } \\
{[\mathrm{m}]}\end{array}$ & $\begin{array}{c}\text { total } \\
{[\mathrm{m}]}\end{array}$ & $\begin{array}{c}\text { error } \\
{[\mathrm{m}]}\end{array}$ & $\begin{array}{c}\text { mean } \\
{[\mathrm{m}]}\end{array}$ & $\sigma$ & $\begin{array}{c}\text { total } \\
\text { error } \\
{[\mathrm{m}]}\end{array}$ & $\begin{array}{c}\text { mean } \\
{[\mathrm{m}]}\end{array}$ & $\begin{array}{c}\sigma \\
{[\mathrm{m}]}\end{array}$ & $\begin{array}{c}\text { rotal } \\
\text { error } \\
{[\mathrm{m}]}\end{array}$ \\
\hline 1 & 4.12 & 2.26 & 6.38 & 3.28 & 2.05 & 5.33 & 2.4 & 1.8 & 4.2 \\
2 & 3.82 & 1.88 & 5.70 & 2.97 & 1.63 & 4.60 & 3.2 & 1.6 & 4.8 \\
3 & 2.77 & 1.11 & 3.88 & 2.97 & 1.38 & 4.34 & 1.7 & 1.1 & 3.8 \\
4 & 3.54 & 1.80 & 5.34 & 3.20 & 1.69 & 4.89 & 1.8 & 1.5 & 3.3 \\
5 & 2.45 & 1.10 & 3.56 & 2.48 & 1.14 & 3.62 & 1.7 & 1.1 & 2.8 \\
6 & 3.16 & 1.61 & 4.78 & 3.35 & 1.83 & 5.17 & 1.5 & 1.0 & 2.5 \\
\hline mean & 3.31 & 1.63 & 4.93 & 3.04 & 1.63 & 4.66 & 2.05 & 1.35 & 3.40 \\
$\sigma$ & 0.64 & 0.46 & 1.09 & 0.32 & 0.32 & 0.62 & 0.64 & 0.33 & 0.91 \\
\hline
\end{tabular}

landscape and distinct topographic features. We have chosen two ICESat-2 RGTs from releases 3 and 4, cycles 1-9. Every ground track crosses up to five DEMs. The least-squares adjustment was calculated independently for the six beams leading to a total of 379 accepted calculations of the 3D translation vectors. The translation vector is a very suitable measure to assess the horizontal accuracy of ICESat-2. Our major results include: (i) the average horizontal error of the ICESat-2 beams estimated from all translation vectors using the latest release 4 is about $4.66 \mathrm{~m}$, well within NASA's specification of $6.5 \mathrm{~m}$; (ii) the relatively large variation of the translation vectors within an observation interval of less than 10 seconds-the time it takes ICESat-2 to traverse the Dry Valleys - indicates a significant horizontal error due to 
high-frequency jitter; (iii) we also notice that the trends are quite different for the individual beams, even within the same beam pair.

Our ICESat-2 horizontal accuracy estimates (average of 4.66 $\mathrm{m}$ with individual beam errors ranging from 3.62 to $5.33 \mathrm{~m}$, release 4) show a remarkable agreement with those presented by [8] and [6]. We extends the study of [8] both spatially and temporarily. The McMurdo Dry Valleys are $2000 \mathrm{~km}$ from their Antarctic site (Array 4, $88^{\circ} \mathrm{S}$ traverse, East Antarctica). We have a total of 16 distinct dates (2 RGTs, each with 8 accepted cycles) compared to the three dates examined by [8]. For the first time, it enabled the temporal variation of ICESat-2's horizontal error on-orbit during an extended period of different sun-orbit geometry (739 days), similar to the prelaunch estimate of $4.9 \mathrm{~m}$ one sigma horizontal error [1], [6].

To shed some light on the question of how valid the results of this study are, on a global scale, we propose that future work shall concentrate on repeating this research in other parts of the world. Additionally we would like to extend the observation period to find analytic function in an attempt to model the temporal variation of the translation vectors. We have treated the translation vectors independently for the six beams, neglecting any constraints that may be applicable from a deeper knowledge on how the beams are physically arranged. Finally, our novel approach allows the regional calibration of ICESat-2 observations using stable terrains reference DEMs. This will facilitate the detection of local elevation changes when a horizontal error of $5 \mathrm{~m}$ would introduce unacceptable vertical errors.

\section{APPENDIX}

The appendix contains the ICESat- 2 granules used in this study.

TABLE VIII

RGT 275 AND RGT 451 GRANULES.

\begin{tabular}{|c|c|c|c|c|}
\hline RGT & C & Date & Granule \\
\hline 275 & 1 & Oct 16 2018 & ATL03_20181016155531_02750110_001_01 \\
275 & 2 & Jan 15 2019 & ATL03_20190115113516_02750210_001_01 \\
275 & 3 & Apr 16 2019 & ATL03_20190416071512_02750310_001_01 \\
275 & 5 & Oct 14 2019 & ATL03_20191014223446_02750510_003_01 \\
275 & 6 & Jan 13 2020 & ATL03_20200113181430_02750610_003_01 \\
275 & 7 & Apr 13 2020 & ATL03_20200413135418_02750710_003_01 \\
275 & 8 & Jul 13 2020 & ATL03_20200713093405_02750810_003_01 \\
275 & 9 & Oct 12 2020 & ATL03_20201012051351_02750910_003_01 \\
451 & 1 & Oct 28 2018 & ATL03_20181028044356_04510112_003_01 \\
451 & 2 & Jan 27 2019 & ATL03_20190127002352_04510212_003_01 \\
451 & 3 & Apr 27 2019 & ATL03_20190427200335_04510312_001_01 \\
451 & 4 & July 27 2019 & ATL03_20190727154312_04510412_003_01 \\
451 & 5 & Oct 26 2019 & ATL03_20191026112310_04510512_003_01 \\
451 & 6 & Jan 25 2020 & ATL03_20200125070255_04510612_003_01 \\
451 & 7 & Apr 25 2020 & ATL03_20200425024243_04510712_003_01 \\
451 & 9 & Oct 23 2020 & ATL03_20201023180215_04510912_003_01 \\
\hline
\end{tabular}

\section{ACKNOWLEDGEMENTS}

This work was funded by NASA Cryospheric Sciences Program in the support of the ICESat-2 mission under the following awards: 80NSSC18K1289 and NNX17AB33G. We thank P Shekhar and I Parmuzin for preprocessing the ICESat2 ATL03 and ATL06 data. Thanks go to A Fountain for helpful discussions about NCALM DEMs.NCALM DEMs were aobtained from the Polar Geospatial Center, University of Minnesota. 


\section{REFERENCES}

[1] T. A. Neumann, A. J. Martino, M. Thorsten, S. Bae, M. R. Bock, A. C. Brenner, K. M. Brunt, J. Cavanaugh, S. T. Fernandes, D. W. Hancock, K. Harbeck, J. Lee, N. T. Kurtz, P. J. Luers, S. B. Luthcke, L. Magruder, T. A. Pennington, L. Ramos-Izquierdo, T. Rebold, J. Skoog, and T. C. Thomas, "The Ice, Cloud, and Land Elevation Satellite-2 Mission: a global geolocated photon product derived from the Advanced Topographic Laser Altimeter System,” Rem. Sens. Env., vol. 233, 2019.

[2] T. Markus, T. Neumann, A. Martino, W. Abdalati, K. Brunt, B. Csatho, S. Farrell, H. Fricker, A. Gardner, D. Harding, M. Jasinski, R. Kwok, L. Magruder, D. Lubin, S. Luthcke, J. Morison, R. Nelson, A. Neuenschwander, S. Palm, S. Popescu, C. K. Shum, B. E. Schutz, B. Smith, Y. K. Yang, and J. Zwally, " The Ice, Cloud, and land Elevation Satellite2 (ICESat-2): Science requirements, concept, and implementation." Rem. Sens. Environ., vol. 190, pp. 260-273., 2017.

[3] B. Smith, H. A. Fricker, A. S. Gardner, B. Medley, J. Nilsson, F. S. Paolo, N. Holschuh, S. Adusumilli, K. Brunt, B. Csatho, K. Harbeck, T. Markus, T. Neumann, M. R. Siegfried, and H. J. Zwally, "Pervasive ice sheet mass loss reflects competing ocean and atmosphere processes," Science, vol. 368, no. 6496, pp. 1239-1242, 2020.

[4] L. Magruder, T. Neumann, H. A. Fricker, S. L. Farrell, K. M. Brunt, A. Gardner, D. Hancock, K. Harbeck, M. Jasinski, N. Kwok, R and. Kurtz, J. Lee, T. Markus, J. Morison, A. Neuenschwander, S. Palm, S. Popescu, B. Smith, and Y. Yang, "New Earth orbiter provides a sharper look at a changing planet," EOS, vol. 100, 2019.

[5] The IMBIE team, "Mass balance of the Antarctic Ice Sheet from 1992 to 2017," Nature, vol. 558, no. 7709, pp. 219-222, 2018.

[6] S. B. Luthcke, T. C. Thomas, T. A. Pennington, T. W. Rebold, J. B. Nicholas, D. D. Rowlands, A. S. Gardner, and S. Bae, "ICESat-2 Pointing Calibration and Geolocation Performance," Earth and Space Science, vol. 8, no. 3, p. e2020EA001494, Mar. 2021.

[7] K. M. Brunt, T. Neumann, and B. E. Smith, "Assessment of ICESat-2 Ice Sheet Surface Heights, Based on Comparisons Over the Interior of the Antarctic Ice Sheet," Geophys. Res. Lett., vol. 13, no. 2, pp. 615-7, 2019.

[8] L. A. Magruder, K. M. Brunt, and M. Alonzo, "Early ICESat-2 onorbit Geolocation Validation Using Ground-Based Corner Cube RetroReflectors," Remote Sensing, vol. 12, no. 21, pp. 3653-21, Nov. 2020.

[9] B. Csatho, T. Schenk, W. Krabill, T. W. Eos, Transactions, and 2005, "Airborne laser scanning for high-resolution mapping of Antarctica," Eos Trans. AGU, vol. 86, no. 25, 2005.

[10] C. F. Martin, "ICESat range and mounting bias estimation over precisely-surveyed terrain," Geophys. Res. Lett., vol. 32, no. 21, 2005.

[11] A. G. Fountain, J. S. Levy, M. N. Gooseff, and D. Van Horn, "The McMurdo Dry Valleys: A landscape on the threshold of change," Geomorphology, vol. 225, no. C, pp. 25-35, 2014.

[12] J. S. Levy, A. G. Fountain, M. K. Obrik, J. Telling, C. Glennie, R. Pettersson, M. Gooseff, and D. J. Van Horn, "Decadal topographic change in the McMurdo Dry Valleys of Antarctica: Thermokarst subsidence, glacier thinning, and transfer of water storage from the cryosphere to the hydrosphere." Geomorphology, vol. 323, pp. 80-97, 2018.

[13] J. S. Levy, A. G. Fountain, J. L. Dickson, J. W. Head, M. Okal, D. R. Marchant, and J. Watters, "Accelerated thermokarst formation in the McMurdo Dry Valleys, Antarctica," Scientific Reports, vol. 3, 2013.

[14] A. Fountain, J. Fernandez-Diaz, M. Obrik, J. Levy, M. Gooseff, D. Van Horn, P. Morinn, and R. Shresta, "High-resolution elevation mapping of the McMurdo Dry Valleys, Antarctica, and surrounding regions." Earth Syst. Sci. Data, vol. 9, pp. 435-443, 2017.

[15] A. J. Martino, M. R. Bock, G. C, F. c, N. T. A, H. D, J. R. L, D. P W, W. C, and L. J, "ATLAS/ICESat-2 L1B Converted Telemetry Data, Version 3," NASA National Snow and Ice Data Center Distributed Active Archive Center, 2019.

[16] S. B. Luthcke, T. Pennington, B. D. Loomis, T. Rebold, and T. C. Thomas, Ice, Cloud, and Land Elevation Satellite 2 (ICESat-2) Project Algorithm Theoretical Basis Document for Precise Orbit Determination, Orbit Design, and Geolocation Parameter Calibration, Version 2. NASA, Goddard Space Flight Center, Greenbelt, MD, 2019.

[17] S. Bae, L. Magruder, N. Smith, and B. Schutz, Ice, Cloud, and Land Elevation Satellite 2 (ICESat-2) Project Algorithm Theoretical Basis Document for Precision Pointing Determination (POD), Version 2. NASA, Goddard Space Flight Center, Greenbelt, MD, 2019.

[18] B. Smith, H. A. Fricker, N. Holschuh, A. S. Gardner, S. Adusumilli, K. M. Brunt, B. Csatho, K. Harbeck, A. Huth, T. Neumann, J. Nilsson, and M. R. Siegfried, "Land ice height-retrieval algorithm for NASA's ICESat-2 photon-counting laser altimeter," Remote Sensing of Environment, vol. 233, p. 111352, 2019.
[19] T. Neumann, A. Brenner, D. Hancock, J. Robbins, J. Saba, K. Harbeck, A. Gibbons, J. Lee, S. Luthcke, T. Rebold, and et al., "ATLAS/ICESat2 L2A Global Geolocated Photon Data, Version 4." Boulder, Colorado USA. NASA National Snow and Ice Data Center Distributed Active Archive Center, 2019

[20] B. Smith, H. Fricker, A. Gardner, M. Siegfried, S. Adusumilli, B. Csath'o, N. Holschuh, J. Nilsson, F. Paolo, and the ICESat-2 Science Team, "ATLAS/ICESat-2 L3A Land Ice Height, Version 4." Boulder, Colorado USA. NASA National Snow and Ice Data Center Distributed Active Archive Center, 2019.

[21] M. A. Hofton, J. B. Blair, S. B. Luthcke, and D. L. Rabine, "Assessing the performance of 20-25 m footprint waveform lidar data collected in ICESat data corridors in Greenland," Geophysical Research Letters, vol. 35, no. 24, p. L24501, 2008

[22] X. Tang, J. Xie, X. Gao, F. Mo, W. Feng, and R. Liu, "The In-Orbit Calibration Method Based on Terrain Matching With Pyramid-Search for the Spaceborne Laser AltimeterThe In-Orbit Calibration Method Based on Terrain Matching With Pyramid-Search for the Spaceborne Laser Altimeter," IEEE Journal of Selected Topics in Applied Earth Observations and Remote Sensing, vol. 12, no. 3, pp. 1053-1062, Mar. 2019.

[23] S. Filin and B. Csatho, "Improvmenet of elevation accuracy for massbalance monitoring using in-flight laser calibration." Ann. Glaciol., no. 34, pp. 330-334, 2002.

[24] S. Filin, "Recovery of Systematic Biases in Laser Altimetry Data Using Natural Surfaces." Photogramm. Eng. Rem. S., vol. 69, no. 11, pp. 1235$1242,2003$.

[25] — "Calibration of spaceborne laser Altimeters-an algorithm and the site selection problem," IEEE Trans. Geosci. Rem. Sens., vol. 44, no. 6 , pp. 1484-1492, 2006.

[26] K. R. Koch, Parameter Estimation and Hypothesis Testing in Linear Models. Springer-Verlag, 1999. 